\title{
A Review on the Assessment of the Spatial Dependence
}

\author{
Pilar García Soidán* \\ Department of Statistics and Operations Research, University of Vigo, Spain
}

Submission: January 11, 2018; Published: March 19, 2018

*Corresponding author: Pilar García Soidán, Department of Statistics and Operations Research, University of Vigo, Campus A Xunqueira, C.P. 36005 Pontevedra, Spain, Tel: +34-986801992; Email: pgarcia@uvigo.es

\begin{abstract}
For intrinsic random processes, an appropriate estimation of the variogram is required to derive accurate predictions, when proceeding through the kriging methodology. The resulting function must satisfy the conditionally negative definiteness condition, both to guarantee a solution for the kriging equation system and to derive a non-negative prediction error. Assessment of the resulting function is typically addressed through graphical tools, which are not necessarily conclusive, thus making it advisable to perform tests to check the adequateness of the fitted variogram.
\end{abstract}

Keywords: Intrinsic stationarity; Isotropy; Variogram

\section{Introduction}

When spatial data are collected, construction of a prediction map for the variable of interest, over the whole observation region, is typically addressed through the kriging techniques [1]. This methodology has been applied in a variety of areas (hydrology, forestry, air quality, etc.) and its practical implementation demands a previous estimation of the data correlation. The latter issue can be accomplished by approximating the variogram function [2], under the assumption that the underlying process is intrinsic, which is the least restrictive stationarity requirement.

However, estimation of the variogram is far from simple. It requires that the resulting function is valid for prediction, namely, that it fulfills the conditionally negative definiteness condition and, in practice, this problem is usually solved through a three-step procedure [3]. To start, a nonparametric method can be employed to obtain the empirical variogram or a kerneltype approach, among other options, although the functions derived in this way are not necessarily valid $[4,5]$. Then, in a second step, a valid parametric model is selected, so that the unknown parameters are estimated to best fit the data by any of the distinct criteria (maximum likelihood, least squares, etc.) provided in the statistics literature. Finally, the adequateness of the fitted variogram function should be checked, by using a cross-validation mechanism or goodness of fit tests. The former procedures are not always conclusive and their use is recommended for comparison of several valid models, rather than for assessment of a unique fit. Also, we could perform a test to determine the appropriateness of a variogram model, as the one introduced in Maglione \& Diblasi [6], for application to random Gaussian and isotropic random processes, or a more general one suggested in García-Soidán \& Cotos-Yáñez [7], which accounts for both the isotropic and the anisotropic scenarios.

An important shortcoming of this three-stage scheme is the choice of the parametric model. The most common options are based on the use of flexible functions, such as the Matérn one, or on the selection of a model "by eye", by comparing the form of the nonparametric variogram with that derived for different valid families, typically used in practice. However this problem becomes more difficult when dealing with anisotropic variograms. Indeed, isotropy conveys that the data correlation depends only on the distance between the spatial sites and not on the direction of the lag vector, unlike the anisotropic assumption. This means that the assessment of isotropy could be a previous step, whose acceptance would simplify the selection of the model and the subsequent variogram computation. In practice, the isotropic property is typically checked through graphical methods, by plotting a nonparametric estimator in several directions, although the latter procedures are not always determinant. Formal approaches to test for isotropy have been introduced in Guan et al. [8] or in Maity \& Sherman [9]. The first test was designed for its application to strictly stationary random processes, whereas the latter one works for more general settings. 


\section{Conclusion}

The need to obtain an adequate variogram estimator demands a deep exploration of the available data. Firstly the isotropic condition should be checked, as this condition would simplify the characterization of the dependence structure. The graphical diagnosis for assessment of this assumption should be accompanied by the performance of some test to determine its acceptance. Then, a nonparametric estimator can be computed and used to derive a valid parametric fit, whose appropriateness can also be evaluated through any of the goodness of fit tests proposed.

\section{References}

1. Goovaerts P (1997) Geostatistics for natural resources evaluation. Oxford University Press, Oxford, UK, p. 483.

2. Cressie N (1993) Statistics for spatial data, Wiley Series in Probability and Mathematical Statistics, New York, USA, p.900.
3. Menezes R, P García Soidán, Febrero Bande M (2006) A comparison of approaches for valid variogram achievement. Computational Statistics 20(4): 623-642.

4. Matheron G (1963) Principles of geostatistics, Economic Geology 58(8): 1246-1266.

5. Hall P, Patil P (1994) Properties of nonparametric estimators of autocovariance for stationary random fields.Probability Theory and Related Fields 99(3): 399-424.

6. Maglione D, Diblasi A (2004) Exploring a valid model for the variogram of an isotropic spatial process. Stochastic Environmental Research and Risk Assessment 18(6): 366-376.

7. García Soidán P, Cotos-Yáñez T (2017) Convergence in distribution of the L2-deviations of the kernel-type variogram estimators with applications. Spatial Statistics 22(2): 338-357.

8. Guan Y, Sherman M, Calvin JA (2004) A nonparametric test for spatial isotropy using subsampling. J Amer Statist Assoc 99: 810-821.

9. Maity A, Sherman M (2012) Testing for spatial isotropy under general designs. J Stat Plan Inference 142(5): 1081-1091.

\section{Your next submission with Juniper Publishers} will reach you the below assets

- Quality Editorial service

- Swift Peer Review

- Reprints availability

- E-prints Service

- Manuscript Podcast for convenient understanding

- Global attainment for your research

- Manuscript accessibility in different formats ( Pdf, E-pub, Full Text, Audio)

- Unceasing customer service

Track the below URL for one-step submission https://juniperpublishers.com/online-submission.php 